\title{
$\begin{array}{ll}\text { Research Square } & \begin{array}{l}\text { Preprints are preliminary reports that have not undergone peer review. } \\ \text { They should not be considered conclusive, used to inform clinical practice, } \\ \text { or referenced by the media as validated information. }\end{array}\end{array}$
}

\section{Weight loss improve pregnancy and livebirth outcomes in young women with early-stage endometrial cancer and atypical hyperplasia:15 years' experience}

\section{yanfang zhang}

Tianjin Medical University First Clinical College: Tianjin Medical University General Hospital https://orcid.org/0000-0003-3610-033X

\section{Dan Li}

Tianjin Medical University First Clinical College: Tianjin Medical University General Hospital

Qi Yan

Tianjin Medical University First Clinical College: Tianjin Medical University General Hospital

\section{Jinghua Wang}

Tianjin Medical University First Clinical College: Tianjin Medical University General Hospital

fei Teng

Tianjin Medical University First Clinical College: Tianjin Medical University General Hospital

\section{Likun Wei}

Tianjin Medical University First Clinical College: Tianjin Medical University General Hospital

huiying zhang ( $\nabla$ huiying_zhang2020@126.com )

Tianjin Medical University First Clinical College: Tianjin Medical University General Hospital

\section{Wenyan Tian}

Tianjin Medical University First Clinical College: Tianjin Medical University General Hospital

\section{Yingmei Wang}

Tianjin Medical University First Clinical College: Tianjin Medical University General Hospital

\section{Xueru Song}

Tianjin Medical University First Clinical College: Tianjin Medical University General Hospital

Fengxia Xue

Tianjin Medical University First Clinical College: Tianjin Medical University General Hospital

\section{Research}

Keywords: Weight loss, Pregnancy outcome, Livebirth outcome, Fertility-sparing therapy, Well-differentiated endometrial cancer, Atypical hyperplasia

Posted Date: March 1st, 2021

DOI: https://doi.org/10.21203/rs.3.rs-259856/v1

License: (1) This work is licensed under a Creative Commons Attribution 4.0 International License. Read Full License 


\section{Abstract}

Background: To evaluate the effects of body weight loss on pregnancy and livebirth outcomes in young women with early-stage endometrial cancer (EC) and atypical hyperplasia (AH) with fertility-sparing therapy. Thus, improve the management of this patient group.

Method: Patients with AH ( $n=36)$ and well-differentiated EC ( $n=8$, FIGO stage IA) who achieved complete regression after conservative treatment were included in this retrospective study. A weight loss group $(n=25)$ and a non-weight loss group $(n=19)$ were divided; while subgroup analysis according to body mass index and stratification analysis according to weight loss proportion were performed to investigate the effect of weight loss on pregnancy and livebirth outcomes. A univariate and multivariate logistic regression analysis were undertaken to analysis the factors associated with pregnancy.

Results: The mean body weight and body mass index at pretreatment of progestin and initiation of fertility treatment was $70.63 \pm 12.03$ and $67.08 \pm 8.18 \mathrm{~kg}$, respectively, and $27.06 \pm 4.44$ and $25.73 \pm 3.15 \mathrm{~kg} / \mathrm{m}^{2}$, respectively. 25 patients $(56.82 \%)$ had weight loss; the median weight loss amount is $5.00 \mathrm{~kg}$ (1.00-34.50), median weigh loss proportion was $6.70 \%(1.00-36.00)$ during median time interval of $12 \mathrm{months}$ (5.0097.00). An impressive favorable pregnancy rate $(65.91 \%)$ and live birth rate $(50.00 \%)$ were achieved. The pregnancy and livebirth rate were meaningfully higher in the weight loss group than the non-weight loss group $(88.00 \%$ vs. $36.84 \%, P=0.000 ; 64.00 \%$ vs. $31.58 \%, P=0.033$, respectively); weight loss $\geq 5 \%$ significantly increased pregnancy and live birth rate in patients with $B M I \geq 25$. The risk ratios of weight loss $\geq 5 \%$ in multivariate logistic analysis for pregnancy was $0.096(0.010,0.907)$.

Conclusions: Weight loss could have a positive effect on pregnancy rates and seem to be useful for improving live birth rates in overweight or obese women with early-stage endometrial cancer and atypical hyperplasia during/after fertility-sparing therapy. weight loss $\geq 5 \%$ was protective factors of pregnancy in fertility-sparing patients with early-stage endometrial cancer and atypical hyperplasia.

\section{Background}

Endometrial carcinoma (EC) and its precursor atypical hyperplasia (AH) classically affect postmenopausal women. However, approximately $5 \%$ of cases of them occur in women aged 40 years or younger. The trend toward late childbearing has made fertility preservation a major issue for women who face EC and $\mathrm{AH}$. Among the affected women, 70\% are nulliparous[1]. NCCN guideline 2018 indicated fertility sparing management may be considered in selected patients and it is consistently recognized that progestin is safe and effective in conservative treatment[2]. Because the ultimate goal of fertility-sparing treatment is childbearing, following high dose progestin therapy and confirmation of the regression of cancer, a favorable pregnancy and livebirth rates in these patients are also clinical concerns. However, an unsatisfying pregnancy and livebirth rate reported recently in a systematic review and meta-analysis was $26.8 \%$ and $20.5 \%$, respectively[3]. Meanwhile, few studies have evaluated the barriers to successful childbearing in these patients. It was known that obesity is a well-known disruptor of the female fertility but evidence is still lacking on whether weight loss interventions improve fertility in patients after fertility-sparing therapy. In the current study, we focused on such subset patients, aim to verify the importance of weight loss to improve pregnancy and livebirth outcomes and provide some procedures in clinical practice and management of those who require fertility-sparing treatment diagnosed with $\mathrm{EC}$ or $\mathrm{AH}$.

\section{Methods}

This retrospective study included women younger than 40 years diagnosed with $\mathrm{EC}$ or $\mathrm{AH}$ who desired fertility-sparing management from May 2005 to May 2019.

Approval was obtained from the Institutional Ethics Committee.

All patients were given full information regarding the risks and benefits of conservative treatments,and all of the patients had signed consents.

Inclusion criteria:(1) histologically proven AH, or well-differentiated EC G1 without myometrial invasion on magnetic resonance imaging (MRI) (2) no signs of extrauterine involvement (3) strong desire to preserve fertility; (4) age $\leq 40$ years old. (5) no contraindication for progestin treatment or pregnancy; (6) good compliance for treatment.

Exclusion criteria: (1) Lynch/hereditary nonpolyposis colorectal cancer (HNPCC) syndrome (2) lost to follow up/data not extractable/ with unavailable data for body weight and height pretreatment of progestin and at imitation of fertility treatment (3) patients achieved complete regression (CR) did not wish to conceive immediately (4) women without a partner when the data was collected.

All patients were pathologically diagnosed by endometrial biopsy through dilation and curettage (D\&C) with hysteroscopy. 
Pathologic diagnosis was reviewed by two experienced gynecological pathologists according to the World Health Organization pathological classification (2014).

Medical records were reviewed for demographic, clinicopathological parameters, oncologic and reproductive data. Blood samples were tested for cancer antigen (CA125), 75g oral glucose tolerance test (OGTT), while fasting blood glucose (FBG), fasting insulin (FINS) for patients with diabetes mellitus. Homeostasis model assessment of insulin resistance (HOMA-IR) index [FBG $(\mathrm{mmol} / \mathrm{L}) \times \mathrm{FINS}(\mu \mathrm{U} / \mathrm{mL}) / 22.5] \geq 2.69 \mathrm{was}$ defined as insulin resistance (IR). Body weights pretreatment (body weight1) of progestin and at initiation of fertility treatment (body weight2) were collected to get body weight change; body mass index (BMI) was calculated and marked as BMI1 and BMI2 respectively. Overweight was defined as $\mathrm{BMI} \geq 25 \mathrm{~kg} / \mathrm{m}^{2}$. and Obesity as $\mathrm{BMI} \geq 30 \mathrm{~kg} / \mathrm{m}^{2}$

Following confirmation of EC or $\mathrm{AH}$, appropriately selected patients who desire fertility preservation were recommended to referred to a reproductive endocrinologist to assess reproductive fertility. In overweight or obesity women, health education was performed and weight loss was recommended.

Patients received a daily oral dose of 250-500 mg medroxyprogesterone acetate (MPA) or 160mg-320mg megestrol acetate (MA). Metformin $1500 \mathrm{mg} /$ day was administered concurrently for patients with insulin resistance. Metformin therapy was continued after progestin administration until conception. Endometrial biopsy through dilation and curettage (D\&C) with hysteroscopy was performed once 3 months after initiating progestin administration. CR was defined as remission with the absence of evidence of hyperplasia or carcinoma. Progestin was continued to the second negative biopsy.

We recommended that the patients undergo infertility treatment as soon as possible after progestin withdrawal. The parameters, which included infertility management, endometrial thickness during ovulation or embryo transfer date, the clinical pregnancy and live-birth outcomes were collected. Clinical pregnancy was defined as observation of a gestational sac on a transvaginal ultrasound scan. Early pregnancy loss including loss of an intrauterine pregnancy < 12 weeks and biochemical pregnancy losses were included also in this study. biochemical pregnancy was diagnosed as Human chorionic gonadotropin $\geq 25 \mathrm{mlU} / \mathrm{mL}$. Endometrial thickness was measured via transvaginal ultrasound.Follow-up period was initiated from the date of progestin withdrawal. All patients were followed till December 2020. The median follow-up period was 86.80 months (12.00-188.50).

Study end-points: weight loss and pregnancy and livebirth outcomes

\section{Results}

\subsection{Patient characteristics}

A total of $36 \mathrm{AH}$ and $8 \mathrm{EC}$ patients who met inclusion criteria were enrolled in. The total patients' characteristics are summarized in Table 1. The median age at diagnosis was 32.00 years; the mean body weight 1 and body weight 2 was $70.63 \pm 12.03 \mathrm{~kg}$ and $67.08 \pm 8.18 \mathrm{~kg}$ respectively; the meanBMI1 and BMI2 was $27.06 \pm 4.44 \mathrm{~kg} / \mathrm{m}^{2}$ and $25.73 \pm 3.15 \mathrm{~kg} / \mathrm{m}^{2} .30(68.18 \%)$ and $23(52.27 \%)$ patients were overweight or obese respectively pre- and post-weight loss. 34(77.27\%) patients were nulligravida and 42(95.45\%) were nulliparity; 33(75.00\%) patients were infertility; the average HOMA-IR was 4.70, 32(72.73\%) patients were diagnosed with insulin resistance and treated with metformin.

23(52.30\%) patients met the criteria for Polycystic ovarian syndrome (PCOS) (Rotterdam 2003 criteria). 9(20.45\%) patients were diagnosed with hypertension and 6(13.64\%) with diabetes mellitus. 25(56.82\%) patients were administrated with MPA and 19(43.18\%) with MA in conservative treatment.

\subsection{Weight loss and reproductive outcomes}

As shown in table 2, the median time interval between the two measurements of body weights was 12 months (range 5-97 months). 25 patients (56.82\%) had weight loss, the median weight loss amount is $5.00 \mathrm{~kg}$ (1.00-34.50), weigh loss proportion was $6.70 \%$ (1.00-36.00). In the patients with $\mathrm{BMI} \geq 25$ and $\mathrm{BMI} \otimes 25 \llbracket$ the median weight loss amount is $5.00 \mathrm{~kg}(1.00-34.50)$ and $3.00(2.00-4.50)$ respectively, and weigh loss proportion was $7.34 \%(1.00-36.00)$ and $5.17 \%(3.00-7.00)$ respectively. 12 patients (27.27\%) had no weight change and 7 (15.91\%) patients had weight gain, the median weight gain was $2.50 \mathrm{~kg}(1.50-10.00)$, all of these 19 patients were regarded as non-weight loss group.

The pregnancy and livebirth rate were significantly increased in weight loss group than non-weight loss group in total 44 patients (88.00\% vs.36.84\%, $P=0.000 ; 64.00 \%$ vs.31.58\%, $P=0.033$, respectively) and patients with $\mathrm{BMl} \geq 25(86.37 \%$ vs. $12.50 \%, P=0.000 ; 59.09 \%$

vs. $0.00 \%, P=0.004$, respectively); In BMI $\mathbb{2} 25$ patients, weight loss a had no effects on pregnancy and livebirth outcomes( $P \otimes 0.05)$. Weight loss was not associated with increased or decreased pregnancy loss $(P \otimes 0.05)$. 
As shown in table 3, in total patients, the pregnancy rate of patients with non-weight loss, weight loss $₫ 5 \%$ and weight loss $\geq 5 \%$ was $36.84 \%$, $80.00 \%$ and $90 \%$, respectively $(P=0.001) ; 12.50 \%, 75.00 \%$ and $88.89 \%$ respectively in overweight and obese patients $(P=0.000)$. Meanwhile, in total patients, the live birth rate of patients with non-weight loss, weight loss $₫ 5 \%$ and weight loss $\geq 5 \%$ was $31.58 \%, 60.00 \%$ and $65.00 \%$, respectively ( $P=0.118) ; 0.00 \%, 50.00 \%$ and $61.11 \%$ respectively in overweight and obese patients $(P=0.010)$.

Associated factors of pregnancy among patients after conservative treatment in univariate analysis shown in table 4 . A $5 \%$ proportion of weight loss was independent protective factors for pregnancy adjusted as age at diagnoses, treatment time of progestin, and endometrial thickness, RR for pregnancy was $0.096(0.010,0.907)$, detailed in table 5.

\subsection{Reproductive outcomes and fertility treatment}

Of 44 patients, 30 patients received the assistance of assisted reproductive technology (ART) and 14 patients attempted natural pregnancy (Non-ART). 29 patients got pregnancy in total. The pregnancy rate was 65.91\% (29/44). 19/29(65.52\%) patients got pregnancy by ART and $10 / 29(34.48 \%)$ spontaneously. It was demonstrated that the pregnancy rate was higher in natural conception patients than women undertaken ART therapy, although the difference was nonsignificant ( $71.43 \%$ vs.63.33\%; $P=0.738)$, and live birth rate was not different (50.00\% vs.50.00\%; $P=1.000$ ) between ART and Non-ART treatment. Of these 29 patients succeeded with 35 clinical pregnancies and 22 gave birth to 26 healthy babies (24singletons and 1twins; 23 full-term and 2 preterm livebirths; 17 girls and 9 boyes;3 patients had given birth twice). The live birth rate was $50.00 \%$ (22/44). There were 6 patients had early intrauterine pregnancy losses and 2 patients had biochemical pregnancy losses, 1 ectopic pregnancy and 1 stillbirth (32 weeks),2 are still in pregnancy until the last follow up. Detailed in Figure 1.

\subsection{Statistical analysis}

All data were presented as means, medians, or proportions. The median values were compared using Mann-Whitney U-test. Frequency distributions were compared using the Chi-squared test or Fisher's exact test. Multivariate analysis was performed in the pregnancy and nonpregnancy groups using endometrial thickness, number of D\&C, duration of progestin, age at diagnosis, hormone level and fasting plasma glucose as independent variables, using a logistic regression to determine the risk ratios. The difference was regarded as statistically significant when $P$-value $₫ 0.05$ in two-sided test. All statistical analyses were performed using SPSS for Mac (version23.0; IBM).

\section{Discussion}

The prevalence of obesity is increasing worldwide, with a corresponding increase in overweight and obese patients referred with infertility. It is well established that obesity is not only the leading risk factor in the development of endometrial cancer and its precancerous lesions; but also, as disruptor of the female fertility, it affects ovulation, oocyte development, maturation and quality, endometrial receptivity, implantation, and even miscarriage[4-6]. But little is known about the impact of weight loss on pregnancy rate and livebirth outcomes in EC and $\mathrm{AH}$ patients who received fertility-preserving treatment. In current study it was demonstrated an impressive favorable pregnancy rate (65.91\%) and live birth rate (50.00\%) after weight loss in fertility-sparing treatment women, which were meaningfully higher than those reported in literature[3, 7]. This study is the first to show that the pregnancy and livebirth rate were significantly higher in weight loss group than non-weight loss one among young women with early-stage endometrial cancer (EC) and atypical hyperplasia (AH).

With the intervention of weight loss, the current study indeed demonstrated more cases of natural pregnancies or pregnancies by ovulation induction occurring soon after conservative treatment, but not In vitro fertilization (IVF) pregnancies. Most of these women in present study suffered from infertility or subfertility with underlying disorders related to overweight/obesity and PCOS, which conditions should be encouraged to seek assisted reproductive therapy (ART) for conception. Studies reported that ART might increase the likelihood of pregnancy than spontaneous way (39.4\% VS 14.9\%) and decreases the interval to conception[3, 8, 9]. But in this study, Non-ART patients achieved the same, even more favorable reproductive outcomes compared to ART group, pregnancy rate $(71.43 \%$ vs $63.33 \%$; $P=0.738)$ and live birth rate $(50.00 \%$ vs $50.00 \%$; $P=0.813)$ respectively. Moreover, only 16 out of 44 patients (patients at advanced age, primary ovarian insufficiency diagnosed, failed to be pregnant by ovulation induction.) required the aid of IVF, and only 9 of the 16 patients who received IVF in the study successfully got pregnant. So far, limited studies, mainly case reports and retrospective studies, have investigated the association between controlled ovarian hyperstimulation and cancer risk, which mainly refer to endometrial and ovarian cancer risk, the conclusions were inconsistent across trials, our understanding is inconclusive given the short follow-up terms and lack of information on important confounders[10-12]. Outcomes in this study indicated that the benefits of weight reduction, including not only improvement in pregnancy rates, but also a reduced need for IVF. So, it is of paramount importance that overweight and obese women are given the necessary advice and support to achieve the weight loss before pregnancy during/after fertility-sparing treatment.

To date, only one research about the significance of weight change on pregnancy and livebirth outcomes in young EC women who undertook fertility preservation treatment is reported[13]. In this study, Park, J Y argued that pre and posttreatment of progestin, BMls and weight 
change were not associated with pregnancy and live birth rates, which is not completely consistent with our results. It was demonstrated in our study that (the data not shown) BMI at pretreatment of progestin and at pretreatment of infertility and weight gain were not associated with pregnancy and live birth rate (additional Table 1), but an improved pregnancy and livebirth outcomes were shown resulting from weight loss.

Firstly, the difference may come from the higher weight loss composition with weight loss interventions in our study, the proportion of weight loss (56.82\%). In Park' study, without weight loss interventions mentioned, a lower weight loss (33.1\%) and higher weight gain (48.1\%) proportion were shown, the BMI posttreatment was higher than pretreatment, i.e., BMls were $25.99 \pm 5.94$ and $25.51 \pm 5.99 \mathrm{~kg} / \mathrm{m}^{2}(P=0.034)$. Secondly, to accurately analyze the relationship between weight change and pregnancy and livebirth outcomes, a subgroup analysis according to BMI was done in current study, which was not included in Park'. A conclusion was drown in subgroup analysis that weight loss meaningfully increased the pregnancy and livebirth rate, especially in overweight and obese patients(BMI $\geq 25)$. Thirdly, a $5 \%$ weight loss proportion in ours according to perform stratification analysis was different from the 10\% proportion which according to in Park' study.

It is unknow what is the differences of weight loss proportion on fertility in patients with $\mathrm{EC}$ and $\mathrm{AH}$ after conservative treatment. In obese women with PCOS only $2-5 \%$ of total body weight loss from baseline is generally accepted as a "clinically meaningful amount" to improve ovulatory function and is more likely to result in spontaneous pregnancy. There is also evidence to support improved outcomes from ovulatory cycles and pregnancy at moderate weight loss (5-10\%) of total body weight loss[14]. Reported for the first time in current study, weigh loss $\geq 5 \%$ was associated with improved pregnancy and livebirth rate, and meanwhile was independent protective factors for pregnancy after adjust as age at diagnosis, duration of progestin, and endometrial thickness. But weigh loss seemed not to associate with decreased pregnancy loss, this may lie in the small cases of this study and it also raises another consideration, what amount of weight loss is necessary to achieve benefit with respect to different medical purposes. Although there are few studies has been done to demonstrate whether it is true that the greater level weight loss the even greater improvement on female fertility, clinicians in medical weight management should bear in mind that the target should be reproductive health improvement, rather than a large number on the scale, different tissues and individual patients respond differently to weight loss. Moreover, consistent with literatures, it was demonstrated that in this study, overweight and obesity before pregnancy increased the pregnancy loss and decreased livebirth rate (data not shown)[15-17]; it was also shown in our data that weight loss was unrelated to an increased risk of pregnancy loss. So, in this sense weight loss is crucial and safe for the clinical management of this patient group.

Progestin therapy is a widely accepted, effective treatment for EC and AH, but paradoxically, weight gain is a well-known side effect[18]. In this study, weight gain was not

evident (15.91\%) and made little influence on reproductive outcomes. Otherwise, most patients achieved weight loss, it perhaps mainly affected by administration of metformin. $72.73 \%$ women in our study commonly used metformin because of insulin resistance. Metformin has been examined in multiple disease processes as a weight gain prevention tool. Metformin appears to impact appetite regulation both directly and indirectly due to its gastrointestinal side effects and a modified microbiome to decreased caloric intake versus increases in energy expenditure[19]. Moreover, health education related non-pharmacological Interventions may take some account of weight loss[20]. In overweight and obese patients in current study, health education was performed and the majority expressed interest in weight loss interventions in person; with a relatively long time to lose weight before pregnancy, 22 patients(73.3\%) lost weight and 18 patients(60\%) achieved $\geq 5 \%$ proportion, which may improve outcomes from ovulatory cycles and pregnancy rate [20]. Just as Ashley F' study about relationship between obesity and endometrial cancer arguing that "a lack of knowledge but opportunity for intervention"[21].

The study demonstrated a significant high incidence of cesarean delivery (22 among 25 pregnancies; 88\%) among women after conservative treatment. To some extent, the increased cesarean rate in these women appears to be associated with hypertensive disorders, macrosomia related to gestational diabetes mellitus which may be associated with a higher BMI pre and during pregnancy,A proper weight loss amount pre-pregnancy and weight gain during pregnancy are crucial to improve obstetric outcomes. Meanwhile with misconception on delivery mode among neoplastic disease survivor, social factors increased the incidence of cesarean delivery. So, caring for these young cancer patients requires collaboration between a dedicated, adherent patient and her medical team of gynecological oncologist, reproductive endocrinologist and obstetric experts.

With the primary limitation of retrospective analysis conducted at a single center and small cases of patients, further large-scale welldesigned RCTs studies are necessary.

\section{Conclusion}

we have demonstrated weight loss may be an effective way to improve the pregnancy and livebirth outcomes in patients with early-stage endometrial cancer and atypical hyperplasia during/after fertility-sparing therapy, especially in overweighted or obese patients. 


\section{Declarations}

\section{Ethics approval and consent to participate}

The study protocol was approved by the Ethics Committee of Tianjin Medical University General Hospital, and all the patients provided informed consent

\section{Consent for publication}

Not applicable

\section{Availability of data and materials}

All data generated or analyzed during this study are included in this published article (and its supplementary information files)

\section{Competing interests}

All authors declare that they have no conflict of interest.

\section{Funding}

This work was supported by grants from the National Natural Science Foundation of China (No.81802617); Tianjin Science and Technology Plan Project(18ZXDBSY00220) and Tianjin Municipal Natural Science Foundation (No.18JCQNJC81200)

\section{Authors' contributions}

Huiying Zhang, Wenyan Tian, Yingmei Wang, Xueru Song, Fengxia Xue: study design and execution; Yanfang Zhang, Dan Li: analysis and interpretation, manuscript preparation, and critical discussion; Qi Yan: data collection and literature retrieval; Jinghua Wang: Statistical analysis; Fei Teng, Likun Wei: assisted with design, data analysis, interpretation. All the authors examined the data and approved the final manuscript.

\section{Acknowledgements}

The authors thank to the assistance of Dr. Jie Liu in data statistics. (Department of Neurology, Tianjin Medical University General Hospital, Tianjin, China; Laboratory of Epidemiology, Tianjin Neurological Institute \& Department of Neurology)

\section{References}

[1]. Soliman, P.T., et al., Risk factors for young premenopausal women with endometrial cancer. Obstet Gynecol, 2005. 105(3): p. 575-580.

[2]. Gallos, I.D., et al., Regression, relapse, and live birth rates with fertility-sparing therapy for endometrial cancer and atypical complex endometrial hyperplasia: a systematic review and metaanalysis. Am J Obstet Gynecol, 2012. 207(4): p. 266.e1-12.

[3]. Li, M., et al., Weight control is vital for patients with early-stage endometrial cancer or complex atypical hyperplasia who have received progestin therapy to spare fertility: a systematic review and meta-analysis. Cancer Manag Res, 2019. 11: p. 4005-4021.

[4]. Best, D., A. Avenell and S. Bhattacharya, How effective are weight-loss interventions for improving fertility in women and men who are overweight or obese? A systematic review and meta-analysis of the evidence. Hum Reprod Update, 2017. 23(6): p. 681-705.

[5]. Wise, M.R., et al., Obesity and endometrial hyperplasia and cancer in premenopausal women: A systematic review. Am J Obstet Gynecol, 2016. 214(6): p. 689.e1-689.e17.

[6]. Silvestris, E., et al., Obesity as disruptor of the female fertility. Reprod Biol Endocrinol, 2018. 16(1):22. doi: 10.1186/s12958-018-0336-z.

[7]. Wei, J., et al., Comparison of fertility-sparing treatments in patients with early endometrial cancer and atypical complex hyperplasia: A meta-analysis and systematic review. Medicine (Baltimore),2017.96(37):e8034:doi: 10.1097/MD.0000000000008034

[8]. Lowe, M.P., et al., Implementation of assisted reproductive technologies following conservative management of FIGO grade I endometrial adenocarcinoma and/or complex hyperplasia with atypia. Gynecol Oncol, 2003. 91(3): p. 569-72. 
[9]. Zhou, R., et al., Prognostic factors of oncological and reproductive outcomes in fertility-sparing treatment of complex atypical hyperplasia and low-grade endometrial cancer using oral progestin in Chinese patients. Gynecol Oncol, 2015. 139(3): p. 424-428.

[10]. Bozdag, G., et al., ICSI outcome following conservative fertility sparing management of endometrial cancer. Reprod Biomed Online, 2009. 18(3): p. 416-420.

[11]. Kim, M.J., et al., Outcomes of in vitro fertilization cycles following fertility-sparing treatment in stage IA endometrial cancer. Arch Gynecol Obstet, 2019. 300(4): p. 975-980.

[12]. Zapardiel, I., et al., Assisted reproductive techniques after fertility-sparing treatments in gynaecological cancers. Hum Reprod Update, 2016. 22(3): p. 281-305.

[13]. Park, J.Y., et al., Significance of body weight change during fertility-sparing progestin therapy in young women with early endometrial cancer. Gynecol Oncol, 2017. 146(1): p. 39-43.

[14]. Crosignani, P.G., et al., Overweight and obese anovulatory patients with polycystic ovaries: parallel improvements in anthropometric indices, ovarian physiology and fertility rate induced by diet. Hum Reprod, 2003. 18(9): p. 1928-1932.

[15]. Cavalcante, M.B., et al., Obesity and recurrent miscarriage: A systematic review and meta-analysis. J Obstet Gynaecol Res, 2019. 45(1): p. 30-38.

[16]. Kawwass, J.F., et al., Extremities of body mass index and their association with pregnancy outcomes in women undergoing in vitro fertilization in the United States. Fertil Steril, 2016. 106(7): p. 1742-1750.

[17]. Boots, C. and M.D. Stephenson, Does obesity increase the risk of miscarriage in spontaneous conception: a systematic review. Semin Reprod Med, 2011. 29(6): p. 507-513.

[18]. Cholakian, D., et al., Effect of oral versus intrauterine progestins on weight in women undergoing fertility preserving therapy for complex atypical hyperplasia or endometrial cancer. Gynecol Oncol, 2016. 140(2): p. 234-238.

[19]. Yerevanian, A. and A.A. Soukas, Metformin: Mechanisms in Human Obesity and Weight Loss. Curr Obes Rep, 2019. 8(2): p. $156-164$.

[20]. Kim, S.Y., E.S. Park and H.W. Kim, Effectiveness of Non-Pharmacological Interventions for Overweight or Obese Infertile Women: A Systematic Review and Meta-Analysis. Int J Environ Res Public Health, 2020. 17(20):7438.doi: 10.3390/ijerph17207438.

[21]. Ryan, D.H. and S.R. Yockey, Weight Loss and Improvement in Comorbidity: Differences at 5\%, 10\%, $15 \%$, and Over. Curr Obes Rep, 2017. 6(2): p. 187-194.

\section{Tables}

Table 1 Patients basic characteristics 


\begin{tabular}{|lc|}
\hline Parameters & Total patients $(n=44)$ \\
\hline Age at diagnosis(years) & $32.00(25.00-40.00)$ \\
\hline Endometrial cancer, $n(\%)$ & $8(18.18)$ \\
\hline Atypical hyperplasia, $n(\%)$ & $36(81.82)$ \\
\hline Infertility, $n(\%)$ & $33(75.00)$ \\
\hline nulligravida, $n(\%)$ & $34(77.27)$ \\
\hline Nulliparous, $n(\%)$ & $42(95.45)$ \\
\hline Homeostasis model assessment of insulin resistance index & $4.70 \pm 3.33$ \\
\hline Insulin resistance, $n(\%)$ & $32(72.73)$ \\
\hline Body weight1(kg) & $70.63 \pm 12.03$ \\
\hline Body weight2(kg) & $67.08 \pm 8.18$ \\
\hline Body mass index1(kg/m $\left.{ }^{2}\right)$ & $27.06 \pm 4.44$ \\
\hline Body mass index2(kg/m $\left.{ }^{2}\right)$ & $25.73 \pm 3.15$ \\
\hline Body mass index1 $\geq 25, n(\%)$ & $30(68.18)$ \\
\hline Body mass index2 $\geq 25, n(\%)$ & $23(52.27)$ \\
\hline Polycystic ovarian syndrome, $n(\%)$ & $23(52.30)$ \\
\hline Hypertension, $n(\%)$ & $9(20.45)$ \\
\hline Diabetes mellitus, $n(\%)$ & $25(56.82)$ \\
\hline Medroxyprogesterone acetate, $n(\%)$ & $19(43.18)$ \\
\hline Megestrol acetate, $n(\%)$ & \\
\hline
\end{tabular}

Body weight1 and Body mass index 1 : Body weight and BMI at pretreatment of progestin Body weight2 and Body mass index2: Body weight and BMI at imitation of infertility

Table 2 Weight loss and reproductive outcomes 


\begin{tabular}{|c|c|c|c|c|c|c|c|c|c|}
\hline & \multicolumn{3}{|c|}{ Total patients $(n=44)$} & \multicolumn{3}{|c|}{ BMI $1 \geq 25(n=30)$} & \multicolumn{3}{|c|}{ BMI1425(n=14) } \\
\hline & $\begin{array}{l}\text { weight loss } \\
(n=25)\end{array}$ & $\begin{array}{l}\text { non-weight } \\
\text { loss } \\
(n=19)\end{array}$ & $\begin{array}{l}P \\
\text { value }\end{array}$ & $\begin{array}{l}\text { weight loss } \\
(n=22)\end{array}$ & $\begin{array}{l}\text { non-weight } \\
\text { loss }(n=8)\end{array}$ & $\begin{array}{l}P \\
\text { value }\end{array}$ & $\begin{array}{l}\text { weight loss } \\
(n=3)\end{array}$ & $\begin{array}{l}\text { non-weight } \\
\text { loss }(n=11)\end{array}$ & $\begin{array}{l}P \\
\text { value }\end{array}$ \\
\hline $\begin{array}{l}\text { Body } \\
\text { weight1(kg) }\end{array}$ & $76.26 \pm 11.37$ & $63.21 \pm 8.46$ & - & $78.23 \pm 10.56$ & $71.50 \pm 5.71$ & - & $61.83 \pm 5.01$ & $57.18 \pm 3.35$ & - \\
\hline $\begin{array}{l}\text { Body } \\
\text { weight2(kg) }\end{array}$ & $68.94 \pm 8.20$ & $64.63 \pm 7.69$ & - & $70.34 \pm 3.62$ & $72.00 \pm 5.89$ & - & $58.67 \pm 4.04$ & $59.27 \pm 2.67$ & - \\
\hline $\operatorname{BMl}\left(\mathrm{kg} / \mathrm{m}^{2}\right)$ & $29.02 \pm 4.07$ & $24.48 \pm 3.55$ & - & $29.83 \pm 3.63$ & $27.84 \pm 2.64$ & - & $23.09 \pm 0.77$ & $22.03 \pm 1.47$ & - \\
\hline BMI2 $\left(\mathrm{kg} / \mathrm{m}^{2}\right)$ & $26.28 \pm 3.09$ & $25.01 \pm 3.18$ & - & $26.83 \pm 2.67$ & $28.03 \pm 2.60$ & - & $22.24 \pm 0.36$ & $22.83 \pm 0.99$ & - \\
\hline $\begin{array}{l}\text { Weight loss } \\
\text { amounts(kg) }\end{array}$ & $\begin{array}{l}5.00(0.50- \\
34.50)\end{array}$ & - & - & $\begin{array}{l}5.00(0.50- \\
34.50)\end{array}$ & - & - & $\begin{array}{l}3.00(2.00- \\
4.50)\end{array}$ & - & - \\
\hline $\begin{array}{l}\text { Weigh loss } \\
\text { ratios (\%) }\end{array}$ & $\begin{array}{l}6.70(1.00- \\
36.00)\end{array}$ & - & - & $\begin{array}{l}7.34(1.00- \\
36.00)\end{array}$ & - & - & $\begin{array}{l}5.17(3.00- \\
7.00)\end{array}$ & - & - \\
\hline $\begin{array}{l}\text { BMI } \\
\text { change }\left(\mathrm{kg} / \mathrm{m}^{2}\right)\end{array}$ & $\begin{array}{l}1.82(0.18- \\
12.37)\end{array}$ & - & - & $\begin{array}{l}2.16(0.18- \\
12.37)\end{array}$ & - & - & $\begin{array}{l}0.77(0.21- \\
1.57)\end{array}$ & - & - \\
\hline $\begin{array}{l}\text { Time } \\
\text { interval(months) }\end{array}$ & $\begin{array}{l}12.00(5.00- \\
97.00)\end{array}$ & - & - & - & - & - & - & - & - \\
\hline Pregnancy $n(\%)$ & $22(88.00)$ & $7(36.84)$ & 0.000 & 19(86.37) & $1(12.50)$ & 0.000 & $3(100.00)$ & $6(54.55)$ & 0.258 \\
\hline Live birth $n(\%)$ & $16(64.00)$ & $6(31.58)$ & 0.033 & 13(59.09) & 0 & 0.004 & $3(100.00)$ & $6(54.55)$ & 0.580 \\
\hline $\begin{array}{l}\text { Pregnancy loss } \\
n(\%)^{\text {a }}\end{array}$ & $7(29.17)^{b}$ & $1(14.29)$ & 0.642 & $7(33.33)^{c}$ & $1(100.00)$ & 0.364 & 0 & 0 & - \\
\hline
\end{tabular}

Weight loss group=patients had weight reduction; Non-weight loss group=patients had no weight change and patients had weight gain. Body weight1 and BMI1: Body weight and BMI at pretreatment of progestin; Body weight2 and BMI2: Body weight and BMI at imitation of infertility

a: pregnancy loss including 6 early intrauterine pregnancy losses and 2 biochemical pregnancy losses; b:7/24=29.17\%,24=22 patients got clinical pregnancy and 2 patients diagnosed as biochemical pregnancy; c:7/21=33.33\%,21=19 patients got clinical pregnancy and 2 patients diagnosed as biochemical pregnancy

Table 3 Body weight loss proportion and pregnancy and live birth outcome

\begin{tabular}{|c|c|c|c|c|c|c|c|c|}
\hline & \multicolumn{4}{|c|}{ Total patients $(n=44)$} & \multicolumn{4}{|c|}{ BMI1 $\geq 25(n=30)$} \\
\hline & $\begin{array}{l}\text { Non-weight } \\
\text { loss }\end{array}$ & 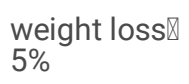 & $\begin{array}{l}\text { Weight } \\
\text { loss } \geq 5 \%\end{array}$ & $\begin{array}{l}P \\
\text { value }\end{array}$ & $\begin{array}{l}\text { Non-weight } \\
\text { loss }\end{array}$ & $\begin{array}{l}\text { weight loss } \rrbracket \\
5 \%\end{array}$ & $\begin{array}{l}\text { Weight } \\
\text { loss } \geq 5 \%\end{array}$ & $\begin{array}{l}P \\
\text { value }\end{array}$ \\
\hline & $(n=19)$ & $(n=5)$ & $(n=20)$ & & $(n=8)$ & $(n=4)$ & $(n=18)$ & \\
\hline $\begin{array}{l}\text { Pregnancy } n \\
\text { (\%) }\end{array}$ & $7(36.84)$ & $4(80.00)$ & 18(90.00) & 0.001 & $1(12.50)$ & $3(75.00)$ & 16(88.89) & 0.000 \\
\hline $\begin{array}{l}\text { Live birth } n \\
\text { (\%) }\end{array}$ & $6(31.58)$ & $3(60.00)$ & $13(65.00)$ & 0.118 & 0 & $2(50.00)$ & $11(61.11)$ & 0.010 \\
\hline
\end{tabular}

BMI1: BMI at pretreatment of progestin

Table 4. Associated factors of pregnancy among patients after conservative treatment in univariate analysis 


\begin{tabular}{|llll|}
\hline Category & Pregnancy & Non-pregnancy & $\boldsymbol{P}$ \\
\hline Age at diagnosis, mean $\pm S D$ (years) & $30.72(4.18)$ & $33.4(2.56)$ & $\mathbf{0 . 0 3 3}$ \\
\hline duration of progestin, mean $\pm S D$ (months) & $5.93(1.19)$ & $8.07(2.71)$ & $<\mathbf{0 . 0 0 1}$ \\
\hline Weight change value, mean $\pm S D(\mathrm{~kg})$ & $-4.83(8.26)$ & $-1.37(4.28)$ & $\mathbf{0 . 0 2 4}$ \\
\hline FBG, mean $\pm S D(\mathrm{mmol} / \mathrm{L})$ & $5.46(0.85)$ & $5.49(1.05)$ & 0.069 \\
\hline number of D\&C, mean $\pm S D$ (times) & $4.48(1.27)$ & $7.13(3.04)$ & $\mathbf{0 . 0 1 4}$ \\
\hline Endometrial thickness, mean $\pm S D(\mathrm{~mm})$ & $9.39(1.34)$ & $7.46(1.8)$ & $<\mathbf{0 . 0 0 1}$ \\
\hline
\end{tabular}

Mann-Whitney U test

number of D\&C: number of dilation and curettage

Table 5. Risk ratios (RR) for pregnancy using logistic regression analysis

\begin{tabular}{|llllllll|}
\hline Category & Reference & \multicolumn{2}{l}{ Univariate analysis } & \multicolumn{4}{c|}{ multivariate analysis } \\
\cline { 3 - 8 } & & $\mathrm{RR}$ & $95 \% \mathrm{Cl}$ & $P$ value & $\mathrm{RR}$ & $95 \% \mathrm{Cl}$ & $P$ value \\
\hline Weight loss ratios & non-weight loss & & & & & & \\
\hline Weight loss $₫ 5 \%$ & & 0.146 & $(0.013,1.578)$ & 0.113 & 0.060 & $(0.001,2.665)$ & 0.177 \\
\hline Weight loss $\geq 5 \%$ & & 0.065 & $(0.011,0.367)$ & 0.002 & 0.096 & $(0.010,0.907)$ & 0.041 \\
\hline
\end{tabular}

Multivariate analysis adjusted as age at diagnosis, duration of progestin, and endometrial thickness

Additional table 1 BMls and Weight gain and reproductive outcomes

\begin{tabular}{|c|c|c|c|c|c|c|c|c|c|c|}
\hline & & \multicolumn{3}{|c|}{ Pregnancy $n(\%)$} & \multicolumn{3}{|c|}{ Pregnancy loss $n(\%)^{\text {a }}$} & \multicolumn{3}{|c|}{ Live birth $n(\%)$} \\
\hline & & Yes (29) & No (15) $P$ V & lue & Yes (8) & No (23) $P$ val & & Yes (22) & No (22) $P$ & $P$ value \\
\hline \multirow[t]{6}{*}{ Total $(n=44)$} & $\begin{array}{l}\text { BMI1 } \\
\geq 25(n=30)\end{array}$ & $20(66.67)$ & $10(33.33)$ & 1.000 & $8(36.36)$ & $14(63.64)$ & 0.068 & 13(43.33) & $17(56.67)$ & 0.195 \\
\hline & $25(n=14)$ & $9(64.29)$ & $5(35.71)$ & & 0 & $9(100.00)$ & & $9(64.29)$ & $5(35.71)$ & \\
\hline & $\begin{array}{l}\text { BMI2 } \\
\geq 25(n=23)\end{array}$ & $13(56.52)$ & $10(43.48)$ & 0.169 & $7(46.67)$ & $8(53.33)$ & 0.015 & 8(34.78) & $15(65.22)$ & 0.035 \\
\hline & $\underset{25(n=21)}{\otimes}$ & 16(76.19) & $5(22.81)$ & & $1(6.25)$ & $15(93.75)$ & & $14(66.67)$ & 7(33.33) & \\
\hline & $\begin{array}{l}\text { Weight } \\
\text { gain yes } \\
(n=7)\end{array}$ & $5(71.43)$ & $2(28.57)$ & 1.000 & $1(20.00)$ & $4(80.00)$ & 1.000 & $4(57.14)$ & $3(42.86)$ & 1.000 \\
\hline & no $(n=37)$ & $24(64.86)$ & $13(35.14)$ & & $7(26.92)$ & 19(73.08) & & 18(48.65) & 19(51.35) & \\
\hline \multirow[t]{2}{*}{$\mathrm{BMI} \geq 25(n=30)$} & $\begin{array}{l}\text { Weight } \\
\text { gain yes } \\
(n=2)\end{array}$ & $1(50.00)$ & $1(50.00)$ & 1.000 & $1(100.00)$ & 0 & 0.364 & 0 & $2(100.00)$ & 0.492 \\
\hline & no $(n=28)$ & 19(67.86) & $9(32.14)$ & & 7(33.33) & $14(66.67)$ & & $13(46.43)$ & $15(53.57)$ & \\
\hline \multirow[t]{2}{*}{ BMI $25(n=14)$} & $\begin{array}{l}\text { Weight } \\
\text { gain yes } \\
(n=5)\end{array}$ & 4(80.00) & $1(20.00)$ & 0.580 & 0 & $4(100.00)$ & - & $4(80.00)$ & $1(20.00)$ & 0.580 \\
\hline & no $(n=9)$ & $5(55.56)$ & $4(44.44)$ & & 0 & $5(100.00)$ & & $5(55.56)$ & $4(44.44)$ & \\
\hline
\end{tabular}

Weight gain: yes=patients with weight gain; no=patients with no body change and patients with weight loss; BMI1: BMI at pretreatment of progestin; BMI2: BMI at initiation of fertility treatment; 
a: pregnancy loss including 6 early intrauterine pregnancy losses and 2 biochemical pregnancy losses

\section{Figures}

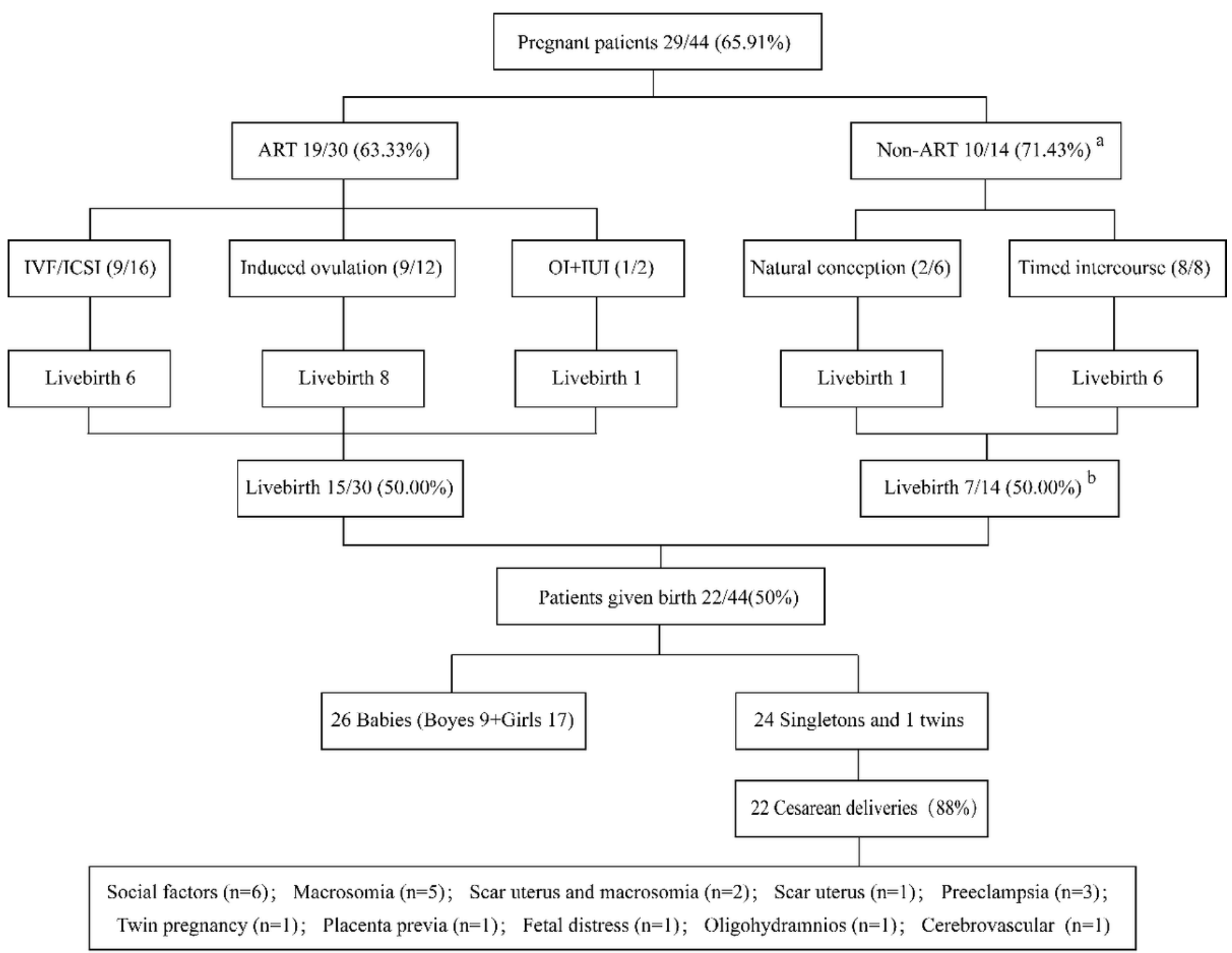

\section{Figure 1}

Infertility treatment after conservative treatment and reproductive outcomes. ART: assisted reproductive therapy; IVF: In vitro fertilization; ICSI: Intracytoplasmic Sperm Injection; OI: ovulation induction; IUI: Intrauterine insemination a: the pregnancy rate of Non-ART patients was not different from the ART patients $(P=0.738)$; $b$ : the livebirth rate of Non-ART patients was same as the ART patients $(P=1.000)$. 